\title{
Global prevalence and mortality of severe Plasmodium malariae infection: a systematic review and meta-analysis
}

\author{
Manas Kotepui ${ }^{1 *}$, Kwuntida Uthaisar Kotepui ${ }^{1}$, Giovanni D. Milanez ${ }^{2}$ and Frederick R. Masangkay ${ }^{2}$
}

\begin{abstract}
Background: Severe complications among patients with Plasmodium malariae infection are rare. This is the first systematic review and meta-analysis demonstrating the global prevalence and mortality of severe P. malariae infection in humans.

Methods: The systematic review and meta-analysis followed the Preferred Reporting Items for Systematic Reviews and Meta-Analyses (PRISMA) guidelines. All research articles published on the severity and mortality of P. malariae infection cases in humans were retrieved from three public databases: PubMed, Scopus, and ISI Web of Science. The pooled prevalence estimate and $95 \%$ confidence interval (Cl) of complications in patients with $P$. malariae malaria was analysed using the random-effects model provided in Stata software. The pooled odds ratio (OR) and 95\% Cl of severe malaria for P. malariae infection and Plasmodium falciparum infection were analysed using Review Manager software.
\end{abstract}

Results: Six studies were used to estimate the pooled prevalence of severe $P$. malariae malaria. Out of 10,520 patients infected with P. malariae, the pooled prevalence estimate of severe P. malariae infection was $3 \%(95 \% \mathrm{Cl} 2-5 \%)$, with high heterogeneity ( $\left.I^{2}: 90.7 \%\right)$. Severe anaemia (3.32\%), pulmonary complications $(0.46 \%)$, and renal impairments (0.24\%) were the most common severe complications found in patients with $P$. malariae infection. The pooled proportion of severe anaemia for $P$. malariae infection and $P$. falciparum infection was comparable among the four included studies (OR: $0.74,95 \% \mathrm{Cl} 0.22-2.45, \mathrm{I}^{2}=98 \%$ ). The pooled proportion of pulmonary complications was comparable between patients with P. malariae infection and those with P. falciparum infection among the four included studies (OR: 1.44; 95\% Cl 0.17-12.31, I': 92\%). For renal complications, the funnel plot showed that the pooled proportion of renal complications for P. malariae infection and P. falciparum infection was comparable among the four included studies (OR: $\left.0.94,95 \% \mathrm{Cl} 0.18-4.93, I^{2}: 91 \%\right)$. The mortality rate of patients with $P$. malariae infection was $0.17 \%$ (18/10,502 cases).

Conclusions: This systematic review demonstrated that approximately two percent of patients with P. malariae infection developed severe complications, with a low mortality rate. Severe anaemia, pulmonary involvement, and renal impairment were the most common complications found in patients with P. malariae infection. Although a low prevalence and low mortality of $P$. malariae infection have been reported, patients with $P$. malariae infection need to be investigated for severe anaemia and, if present, treated aggressively to prevent anaemia-related death.

Keywords: Severe, Complications, P. malariae, Quartan malaria

*Correspondence: manas.ko@wu.ac.th

${ }^{1}$ Medical Technology, School of Allied Health Sciences, Walailak University, Tha Sala, Nakhon Si Thammarat, Thailand

Full list of author information is available at the end of the article

\section{Background}

Malaria is a public health problem, with an estimated 219 million cases in 87 countries, and 435,000 malaria-related deaths were estimated in 2017 [1]. The highest prevalence 
is in the World Health Organization (WHO) African Region [1]. There are five major Plasmodium species which can infect human beings, including Plasmodium falciparum, Plasmodium vivax, Plasmodium malariae, Plasmodium ovale, and Plasmodium knowlesi [2]. The transmission of malaria in humans occurs through the bite of a female Anopheles mosquito [2]. In addition, blood transfusion and maternal transmission have been demonstrated as other routes of malaria infection with less frequent occurrences [3].

Most malaria diseases in humans are caused by P. falciparum and $P$. vivax [4]. Both species were geographically present in the southeastern and western Pacific regions, with a higher distribution of $P$. falciparum than $P$. vivax in Africa, while $P$. vivax is more prevalent than $P$. falciparum in South America [5]. P. ovale infection is widespread principally in tropical Africa, whereas $P$. knowlesi infection occurs only in certain forested areas of Southeast Asian countries [5]. P. malariae is frequently co-endemic with P. falciparum in sub-Saharan Africa, South America, Indonesia, Southeast Asia, and the western Pacific [6]. A previous study found that $7.4 \%$ of $P$. malariae infections were mixed infections with $P$. falciparum [7].

Severe malaria is any complication of Plasmodium species infection that develops rapidly and leads to death within hours or days [8], and these complications were listed by the WHO [9]. Most severe malaria-related deaths are caused by $P$. falciparum, while $P$. vivax or $P$. ovale can also induce severe complications resulting in death but less frequently than P. falciparum [10]. Severe malaria is a rare complication that occurs in patients with P. malariae infection [11], including acute kidney injury [12-15], cerebral malaria [16], and prostrated and multiple convulsions [17]. This is the first systematic review and meta-analysis to demonstrate the prevalence of severe $P$. malariae infection among patients using articles published in three research databases.

\section{Methods}

Literature search

The systematic review and meta-analysis followed the Preferred Reporting Items for Systematic Reviews and Meta-Analyses (PRISMA) guidelines [18]. All research articles published on the prevalence of severe $P$. malariae cases in humans were retrieved from three public databases: PubMed, Scopus, and ISI Web of Science. The published articles were searched up to 31 December 2019. The search terms were "(severe OR complicated OR Complication) AND ("Plasmodium malariae" OR malariae)" using Boolean operators "OR" or "AND". EndNote software version X7 (Thomson Reuters, New York,
NY) was used to process all references in the present study.

\section{Eligibility criteria}

The inclusion criteria were any study that reported severe $P$. malariae infection and any primary study published in the English language. Only articles reporting severe $P$. malariae mono-infection were included. Those included studies were used to analyse the pooled prevalence of severe $P$. malariae malaria. Malaria diagnosis was based on one of the following methods: microscopy, rapid diagnostic test (RDT), and polymerase chain reaction (PCR).

Exclusion criteria were any study reporting $P$. malariae infection with no related topics/no complications, animal studies, drug studies, case reports and case series, editorials, letters, proceedings, short communications, experimental studies, malaria in pregnancy, co-infection with P. malariae and other Plasmodium species or other diseases, and review articles. Studies were also excluded if they reported incomplete data on severe $P$. malariae infection.

\section{Data selection and extraction}

Two reviewers (MK and KUK) selected the article independently. Any discrepancy between two reviewers about article selection was resolved by discussion or by requesting the opinion of the third reviewer (GDM). The data set of this systematic review and meta-analysis, including the name of the author(s), publication year, study period, age distribution, haemoglobin concentration, parasitaemia level, nephrotic syndrome, albuminuria, the number of all malaria cases for each species, mortality rate, and the number of severe cases of all Plasmodium species, were extracted into Microsoft Excel spreadsheets (Microsoft Corporation, USA) for further analysis.

\section{Criteria of severe malaria}

The criteria of severe $P$. malariae malaria were based on the WHO definition among the included studies [8].

\section{Quality of included studies}

A quality assessment was performed following the quality assessment tool developed by the Newcastle-Ottawa Scale (NOS) for assessing the quality of nonrandomized studies in meta-analyses [19]. The quality assessment tool was used to evaluate the validity of the included studies, which is also shown in Table 3.

\section{Statistical analysis and meta-analysis}

Qualitative variables, including the number of patients with severity signs, the number of deaths, and the number of patients infected with Plasmodium spp., were 
analysed using the frequency and percentage. Data in Microsoft Excel spreadsheets were transferred into Stata version 14 (StataCorp, USA) for calculating the pooled prevalence and 95\% confidence interval (CI) of complications in patients with severe $P$. malariae malaria. The pooled prevalence estimate of severe $P$. malariae infection was calculated using the number of patients with severe malaria and the number of patients with $P$. malariae malaria. The pooled proportion of severe complications for $P$. malariae infection was calculated using the number of severe complications among patients with $P$. malariae, and the total number of severe complications among patients infected with all Plasmodium spp., which have been reported in the included studies. The estimation of the pooled prevalence was following a previous research guideline [20]. The command in Stata was "metaprop case population, random". Moreover, the summary odds ratio (OR) and $95 \% \mathrm{CI}$ were calculated to present the difference in the proportion of severe $P$. malariae infection compared with non-malariae infection and were also determined using Review Manager (RevMan) (Cochrane Collaboration, UK). The degree of heterogeneity between the included studies was assessed using Cochran's Q test and Moran's I ${ }^{2}$ (inconsistency), with $\mathrm{I}^{2}$ values of more than $50 \%$ indicating substantial heterogeneity.

\section{Publication bias}

Funnel plot analysis was used to demonstrate any symmetry in the funnel plots among patients with $P$. malariae infection and to evaluate whether publication bias was the underlying cause of data heterogeneity in the included studies.

\section{Results}

\section{Characteristics of included studies}

After searching for possible related studies, a total of 1835 studies were retrieved. Among those 1835 studies, 236 duplicate studies were removed. Then, 1599 studies were screened by title and abstracts, and 1273 studies were excluded, including 677 articles not related to P. malariae, 89 book and book chapters, 24 conference papers, 39 editorials/letters/correspondence articles, 39 note articles, and 444 review articles. The full texts of a total of 326 articles were screened for eligibility, and 320 were excluded, including 81 non-severe $P$. malariae, 72 experimental studies, 62 non-P. malariae, 23 no full-text, 14 entomological studies, 13 mixed infection of P. malariae with other Plasmodium species, 11 Pregnant participants, 10 drug research and clinical trials, 7 animal studies, 7 non-English language, 7 case reports of severe $P$. malariae, 6 case reports of non-severe $P$. malariae, 5 case reports of non-P. malariae, and 2 knowledge assessment. Six articles were included in the final qualitative and quantitative analysis (Fig. 1). All characteristics of the included studies are demonstrated in Table 1. Among the six included studies, five studies were observational cross-sectional designs in which data were retrieved from hospitals $[21,22]$ or national medical records [23-25]. One study was a prospective cohort study conducted in Belgium during 2000-2005 [26]. In the present systematic review and meta-analysis, two included studies were conducted in Belgium and Sweden, European countries [25, 26]; two were conducted in Indonesia, an Asian region [21, 22]; one in the USA, North America [24]; and one in Colombia, South America [23]. Data on the haemoglobin concentration $(\mathrm{g} / \mathrm{dl})$, nephrotic syndrome, albuminuria, age distribution, and parasitaemia level are shown in Additional file 1.

\section{The crude prevalence of severe $P$. malariae infection and severe non-malariae infection}

All six included studies reported a total of 10,520 patients with $P$. malariae infection. The lowest number of cases of $P$. malariae infection was 16 patients in a study conducted by Bottieau et al. [25], while the highest number of cases of $P$. malariae infection was 5097 patients in a study by Langford et al. [22]. Among the 10,520 patients who were infected with $P$. malariae, three hundred and sixty (3.4\%) developed severe $P$. malariae infection (Table 1). The included studies reported patients with $P$. falciparum (193,846 cases), P. vivax (189,931 cases), $P$. ovale (1355 cases), and mixed infection (41,457 cases). The crude severity rates of infections with other Plasmodium spp. were $4.57 \%$ P. falciparum (four studies), $1.26 \%$ P. vivax (five studies), $2.59 \%$ P. ovale (four studies), and $4.83 \%$ mixed infection. The number of severity signs of patients with $P$. malariae and other Plasmodium spp. infection are demonstrated in Table 2. Severe anaemia was the most common severe complication found among patients with $P$. malariae infection (349 cases, 3.32\%). Severe anaemia was also the most common complication found in P. falciparum (3.86\%), P. vivax (1.52\%), P. ovale (0.66\%), and mixed infection (4.73\%). Pulmonary complications $(0.46 \%)$ and renal impairment $(0.24 \%)$ were the second and third most common complications found in patients with $P$. malariae infection, respectively.

\section{The pooled prevalence estimate of severe $P$. malariae malaria}

The number of patients with severe $P$. malariae infection and the total number of patients with $P$. malariae infection were used to estimate the pooled prevalence of severe $P$. malariae infection (Additional file 2). The pooled prevalence estimate of severe $P$. malariae infection was $3 \%$ (95\% CI 2-5\%), with high heterogeneity $\left(\mathrm{I}^{2}\right.$ : 


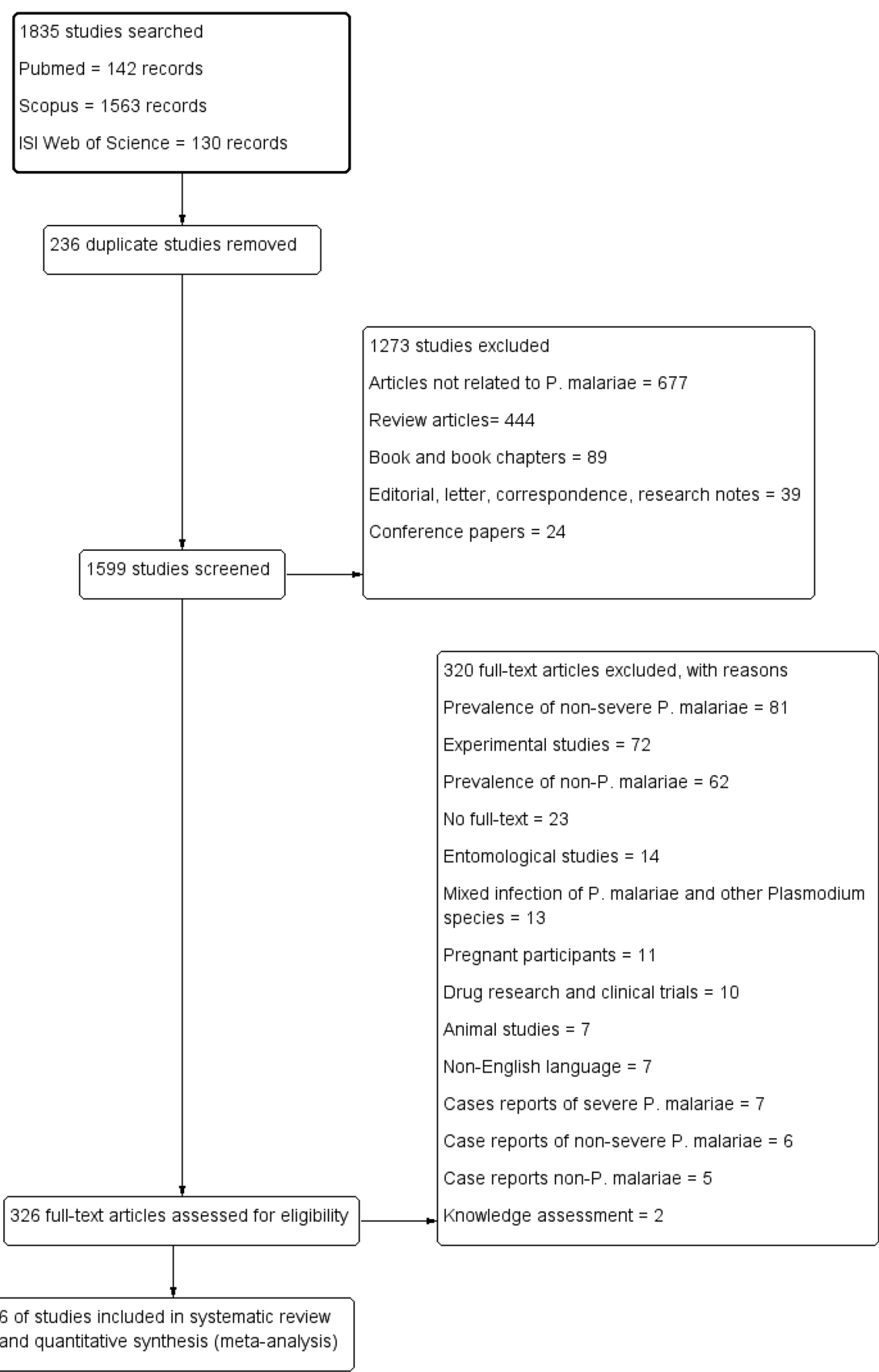

Fig. 1 Flowchart for study selection 


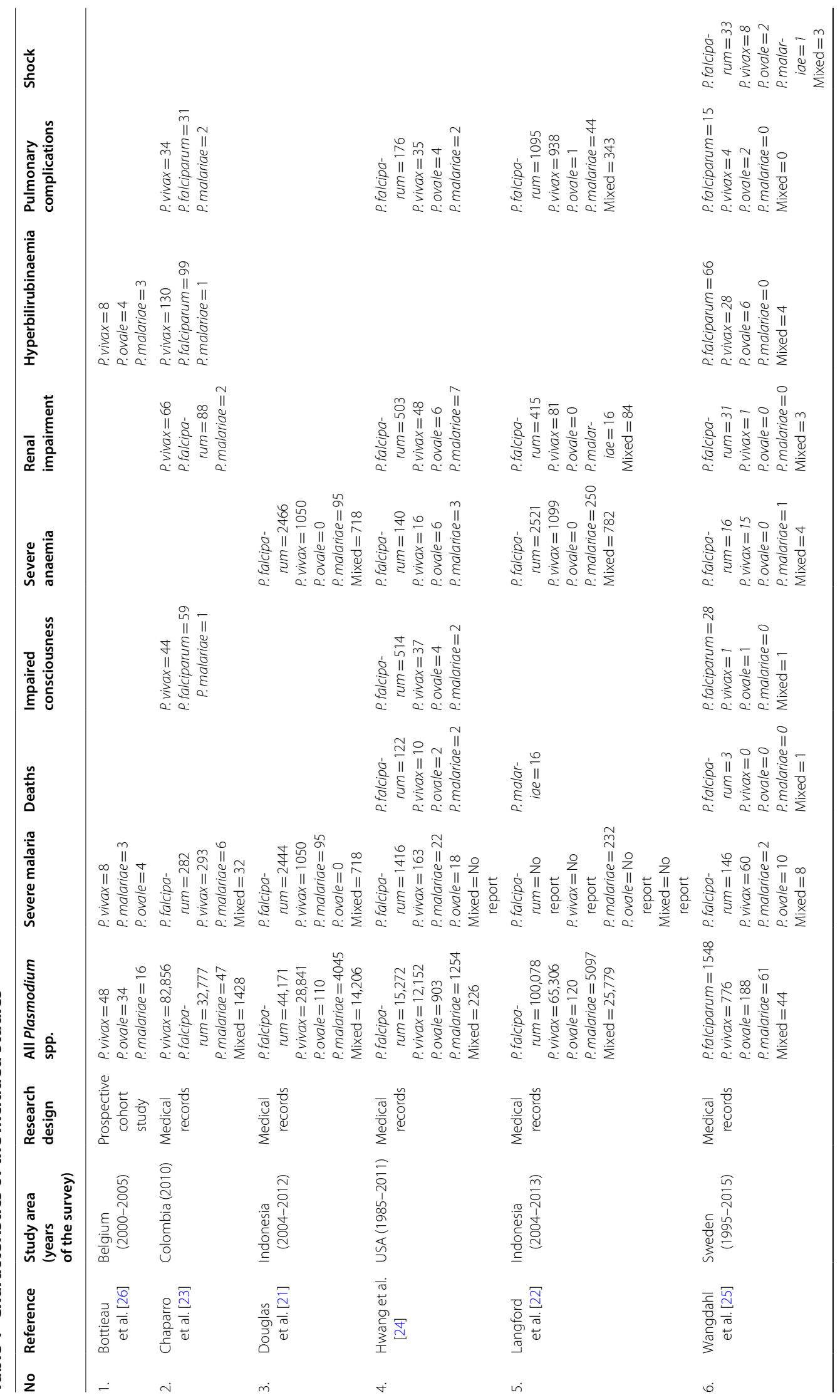




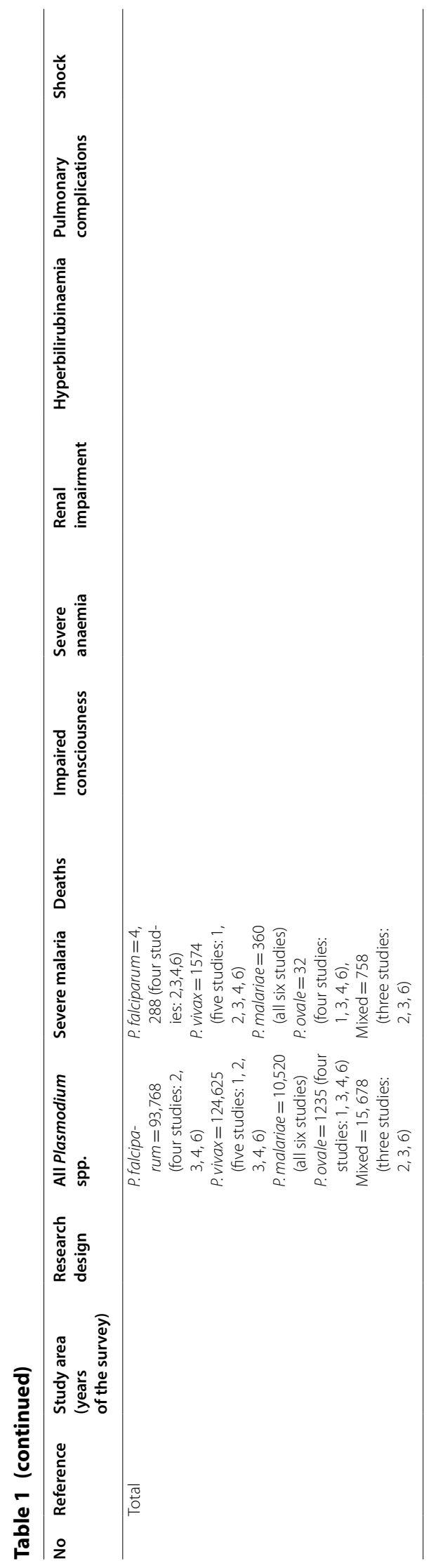


Table 2 Complications presented with P. malariae and other Plasmodium spp.

\begin{tabular}{|c|c|c|c|c|c|}
\hline \multirow{2}{*}{$\begin{array}{l}\text { Major complication } \\
\text { (WHO, 2014) }\end{array}$} & \multicolumn{5}{|c|}{ Number of severity signs (severity rate, \%) } \\
\hline & $\begin{array}{l}\text { P. malariae }(\mathrm{N}=10,520 \\
\text { cases, } 6 \text { studies) }\end{array}$ & $\begin{array}{l}\text { P. falciparum }(\mathrm{N}=193,846 \\
\text { cases, } 5 \text { studies: } 2,3,4,5,6)\end{array}$ & $\begin{array}{l}\text { P. vivax }(\mathrm{N}=189,931 \\
\text { cases, } 6 \text { studies) }\end{array}$ & $\begin{array}{l}\text { P. ovale } \\
(\mathrm{N}=1355 \\
\text { cases })\end{array}$ & $\begin{array}{l}\text { Mixed infection } \\
(\mathrm{N}=41,457 \\
\text { cases })\end{array}$ \\
\hline Acidosis & 0 & $21(0.01)$ & 0 & 0 & 0 \\
\hline Pulmonary/lung & $48(0.46)$ & $1317(0.68)$ & $1011(0.53)$ & $7(0.52)$ & $343(0.83)$ \\
\hline Death & $18(0.17)$ & $122(0.06)$ & $10(.0050)$ & $2(0.15)$ & $1(0.002)$ \\
\hline Cerebral malaria & $3(0.03)$ & $601(0.31)$ & $82(0.04)$ & $5(0.37)$ & $1(0.002)$ \\
\hline Convulsions & 0 & $9(0.005)$ & 0 & 0 & 0 \\
\hline Renal impairment & $25(0.24)$ & $1037(0.53)$ & $218(0.11)$ & $6(0.44)$ & $87(0.21)$ \\
\hline Prostration & 0 & $9(0.005)$ & $1(0.0005)$ & 0 & 0 \\
\hline Hypotension/shock & $1(0.01)$ & $33(0.02)$ & $8(0.004)$ & $2(0.15)$ & $3(0.007)$ \\
\hline Jaundice & $4(0.04)$ & $165(0.09)$ & $166(0.09)$ & $6(0.44)$ & $4(0.01)$ \\
\hline Severe anaemia & $349(3.32)$ & 7473 (3.86) & $2886(1.52)$ & $9(0.66)$ & $1961(4.73)$ \\
\hline Bleeding/DIC & 0 & $17(0.009)$ & $5(0.003)$ & $1(0.07)$ & $1(0.002)$ \\
\hline Hyperparasitaemia & 0 & $57(0.03)$ & 0 & 0 & $3(0.007)$ \\
\hline Hypoglycaemia & 0 & $2(0.001)$ & 0 & 0 & 0 \\
\hline Total & $448(4.26)$ & $10,842(5.59)$ & $4387(2.31)$ & $38(2.8)$ & $2404(5.8)$ \\
\hline
\end{tabular}

90.67\%, $\mathrm{P}<0.001$ ), using random-effects analysis (Fig. 2). The highest proportion of severe P. malaria infection was found in a study by Bottieau et al. (19\%, 95\% CI 7-43\%) [26].

\section{The pooled prevalence estimate of complications for $P$. malariae malaria}

The number of severe complications among patients with $P$. malariae, and the total number of severe complications among patients infected with all Plasmodium spp. were used to estimate the pooled proportion of severe complications for $P$. malariae infection in comparison to those with Plasmodium spp. (Additional file 3). The pooled proportion of severe complications for $P$. malariae infection in comparison to those with Plasmodium spp. was demonstrated in Fig. 3. Overall, the pooled proportion of severe complications in patients with $P$. malariae infection was $2 \%$ (95\% CI 1-3\%). The highest proportion of severe complications caused by $P$. malariae infection in comparison to other Plasmodium spp. was severe anaemia (3\%, 95\% CI 2-3\%).

\section{The pooled proportion of severe anaemia for $P$. malariae infection and $P$. falciparum infection}

The pooled OR of severe anaemia for $P$. malariae infection and $P$. falciparum infection was comparable among the four included studies (OR: 0.74, 95\% CI 0.2245-2., $\mathrm{I}^{2}=98 \%$ ) (Fig. 4). The proportion of severe anaemia in $P$. malariae infection was lower than in P. falciparum infection in a study by Douglas et al. (OR: $0.41,95 \%$ CI 0.33-0.50) [21], and Hwang et al. (OR: 0.26, 95\% CI 0.08-0.81) [24]. The proportion of severe anaemia in $P$. malariae infection was higher than that in $P$. falciparum infection in a study by Langford et al. (OR: 2.00, 95\% CI 1.75-2.28) [22].

The pooled proportion of pulmonary and renal complications for $P$. malariae infection and $P$. falciparum infection

The pooled proportion of pulmonary complications was comparable between patients with $P$. malariae infection and those with $P$. falciparum infection among the four included studies (OR: 1.44; 95\% CI 0.17-12.31, $\mathrm{I}^{2}$ : 92\%) (Fig. 5). Pulmonary complications were lower in $P$. malariae infection than in P. falciparum infection in a study by Hwang et al. (OR: 0.14; 95\% CI 0.03-0.55) [24], while pulmonary complications were higher in $P$. malariae infection than in $P$. falciparum infection in the study by Chaparro et al. (OR: 46.95; 95\% CI 10.9202.1) [23]. For renal complications, the funnel plot showed that the pooled proportion of renal complications for $P$. malariae infection and $P$. falciparum infection was comparable among the four included studies $\left(\mathrm{OR}=0.94,95 \%\right.$ CI $0.18-4.93, \mathrm{I}^{2}$ : 91\%) (Fig. 6). Renal complications were lower in patients with $P$. malariae infection than in those with $P$. falciparum infection in the study by Hwang et al. (OR: 0.16; 95\% CI 0.080.35) [24], while renal complications were higher in patients with $P$. malariae infection than in those with 


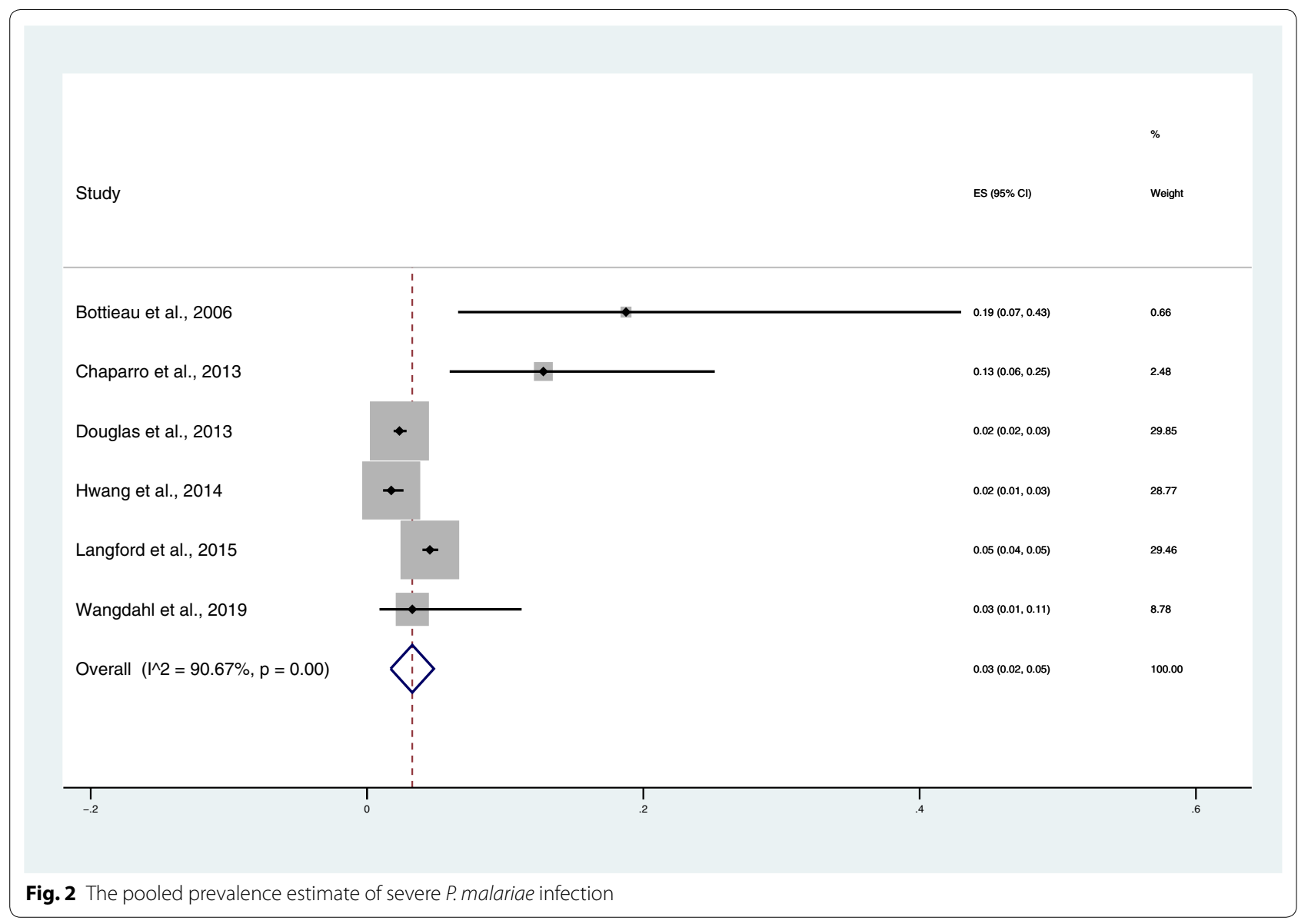

P. falciparum infection in the study by Chaparro et al. (OR: 16.51; 95\% CI 3.94-69.1) [23].

\section{The mortality of $P$. malariae infection}

The crude mortality rate of $P$. malariae infection was $0.17 \%$ (18 cases), as reported in the included studies by Hwang et al. [24], and by Langford et al. [22]. The crude mortality rates of infections with other Plasmodium spp. reported by the included studies were $P$. falciparum (122 cases, $0.08 \%), P$. vivax (10 cases, $0.01 \%)$, P. ovale ( 2 cases, $0.15 \%)$, and 1 case of mixed infection $(0.002 \%)$.

\section{Quality of included studies}

All six studies included in the present study were rated according to the NOS guidelines. Overall, five studies were rated good, with a maximum of nine stars, and one study was rated medium with eight stars because of their "Representativeness of the cases" (presented only severe anaemia complications in their study, with no other complications in their objectives). The rating details are provided in Table 3.

\section{Publication bias}

The funnel plot analysis to demonstrate the publication bias among the six included studies could not be performed, as the analysis required a minimum of 10 studies [27].

\section{Discussion}

This is the first systematic review and meta-analysis demonstrating the pooled prevalence estimate of severe $P$. malariae infection. The results demonstrated that the pooled prevalence estimate of severe $P$. malariae malaria was low (3\%). These results were in accordance with a previous study indicating that severe $P$. malariae infection was a rare complication with less frequent occurrence in malarial patients [11]. The mechanism of severe malaria among $P$. malariae infections is unknown. $P$. malariae is a slow-growing parasite infecting mature red blood cells [28]. It can result in a lower number of merozoites produced per 72-h erythrocytic cycle, called quartan or tertian malaria, inducing the earlier development of human immunity [6]. P. malariae is not the cause of malarial relapse from persistent liver-stage parasites, but 


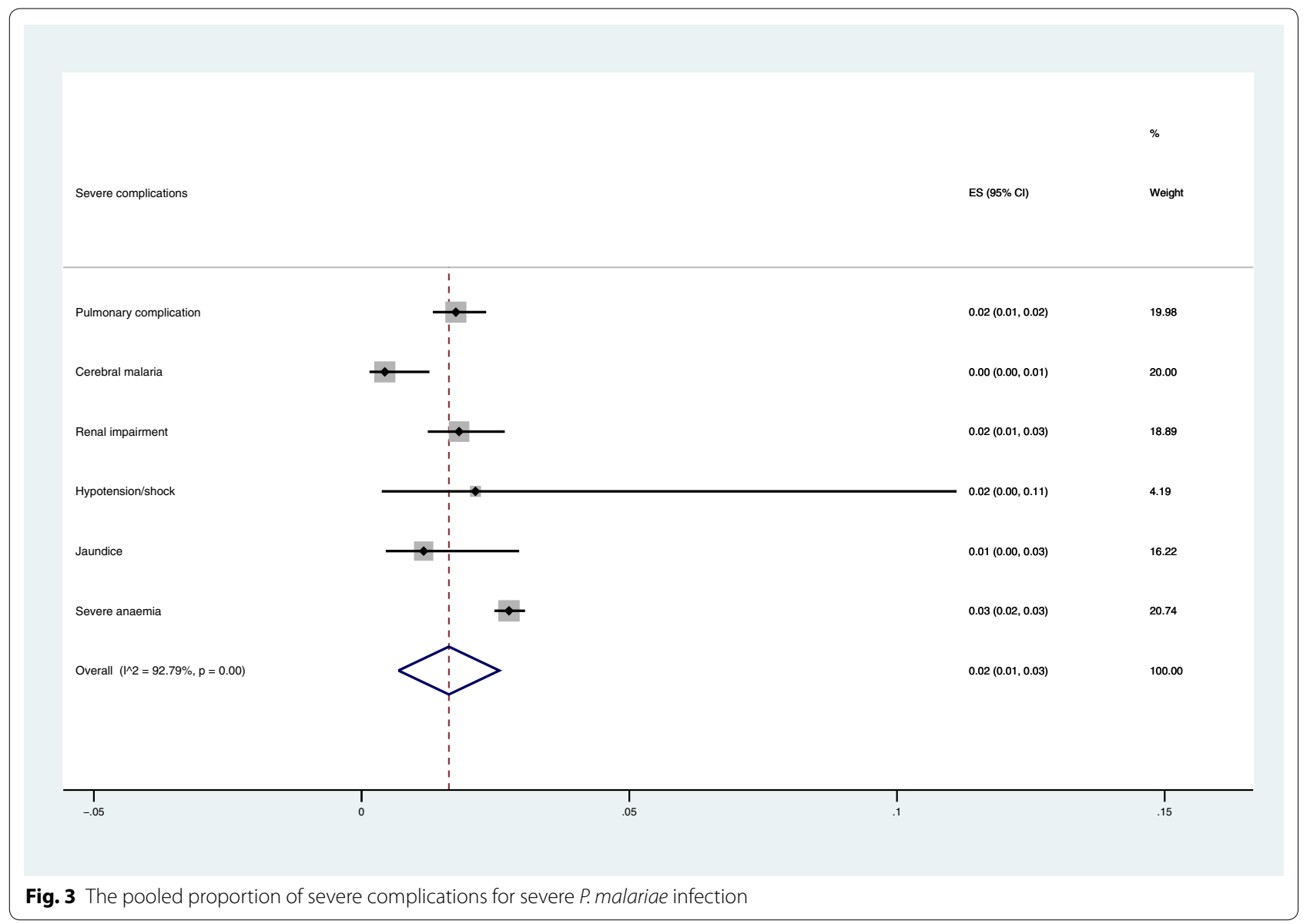

the recrudescence of blood-stage parasites can persist for long periods without signs or symptoms. Even with appropriate treatment, chronic subclinical $P$. malariae infection can occur because of its extended prepatent period when the inadequate drug in the blood cannot eliminate newly emerging merozoites $[28,29]$. As most patients infected with $P$. malariae infections have no sign or symptoms of malaria, they have no need for health services during their asymptomatic infection [30]. Even though patients suspected of having $P$. malariae infections visit the health service, $P$. malariae parasites are missed by light microscopy due to their low parasite density compared to that of $P$. falciparum parasites [31, 32]. It is also difficult to distinguish $P$. malariae from

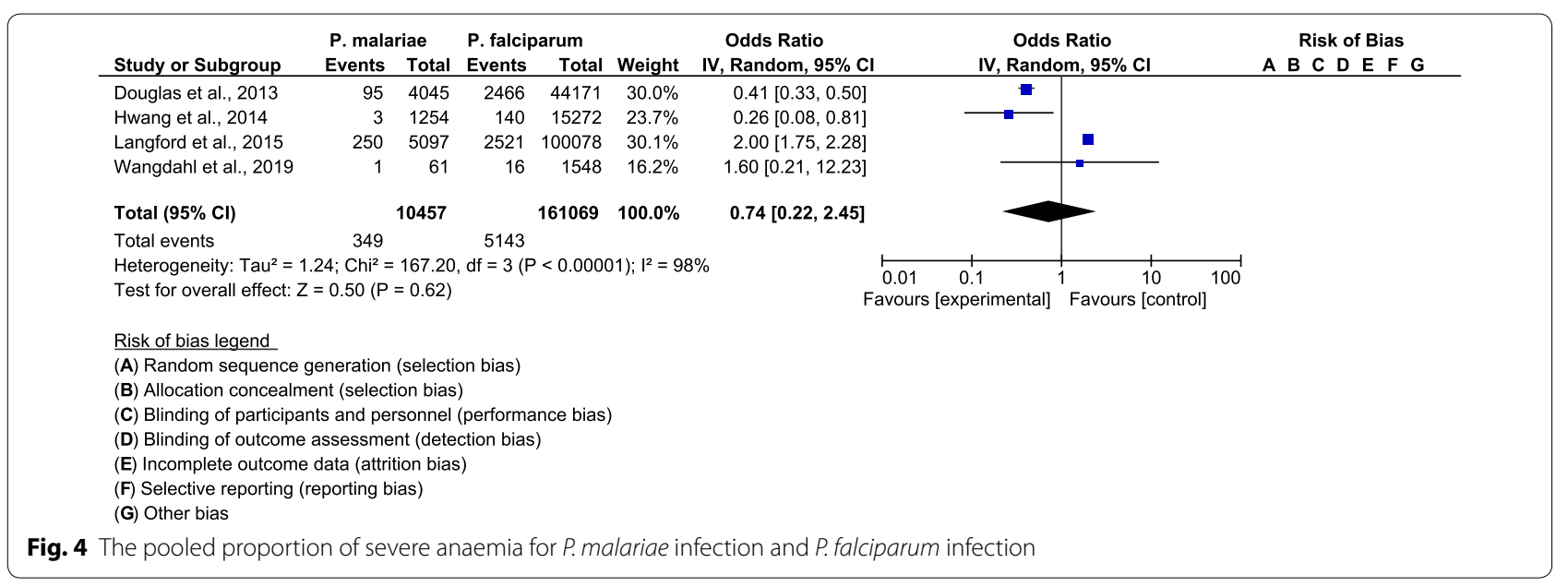




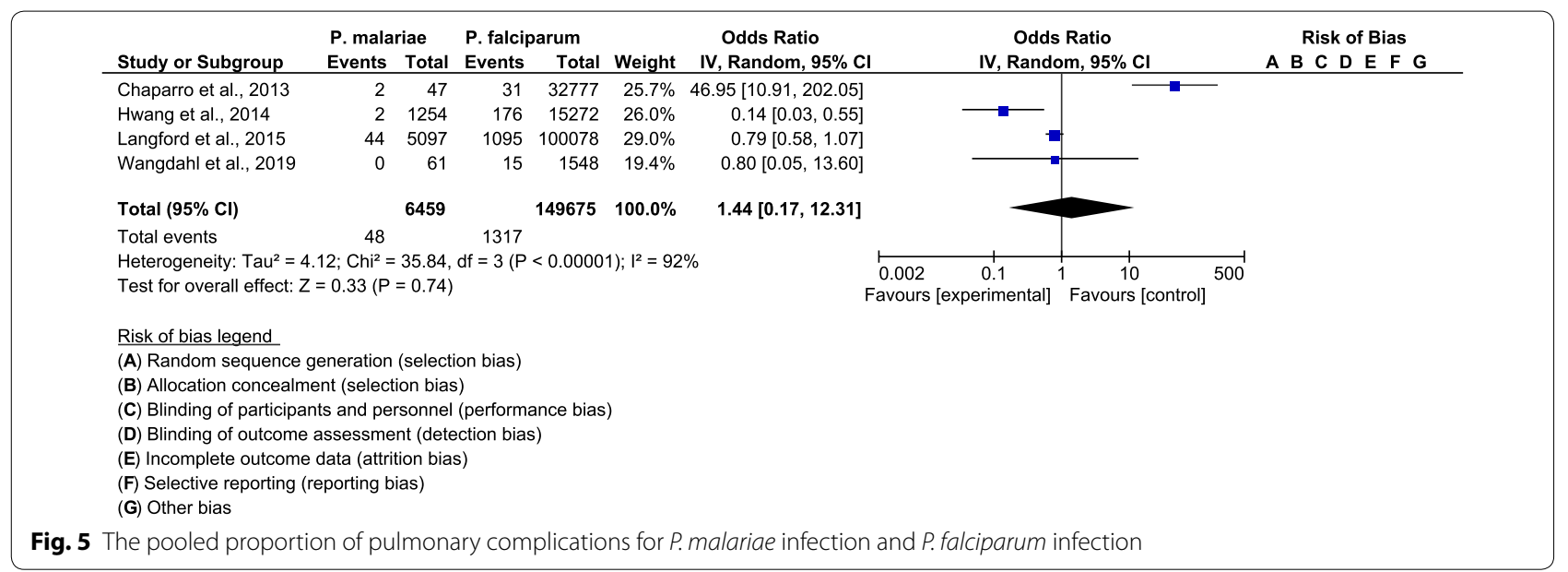

other Plasmodium species using a microscopic method, and its prevalence may be underestimated, resulting in late disease presenting severe complications [17, 33]. In addition, $P$. malariae infection can easily be misdiagnosed when microscopy is used for detection and is often treated as a bacterial infection [12]. The detection of $P$. malariae by microscopy in patients with mixed infection with $P$. falciparum in endemic areas where $P$. falciparum predominates is also difficult, as, in the area of malaria endemicity in Africa, infections of $P$. malariae can frequently be mixed with $P$. falciparum infections [6]. Another possible cause of severe malaria in patients with $P$. malariae infection is rosette formation, i.e., the binding of two or more infected red cells to an uninfected red cell, which is associated with microcirculatory blood flow obstruction in P. falciparum infection and has been reported in patients with $P$. malariae infection [17].

The present systematic review and meta-analysis demonstrated that severe anaemia was the most common complication in patients with $P$. malariae infection, as reported by the included studies. The included study by Douglas et al. [21], demonstrated that the proportion of severe anaemia in $P$. malariae infection was lower than that in non-P. malariae infection. They indicated that $P$. malariae infection was associated a lower mean haemoglobin level than infection with other Plasmodium spp., [21]. The included study by Langford et al., 2015, enrolled 5097 patients with $P$. malariae infections and demonstrated that the mean haemoglobin concentration was lower $(9.0 \mathrm{~g} / \mathrm{dl})$ in patients with $P$. malariae infection than in those with infection with all other Plasmodium species [22]. Nevertheless, the lower haemoglobin concentrations associated with a greater risk of death were reported in patients with $P$. falciparum infection [21]. This causation of anaemia in malarial patients might be due to the higher parasitaemia level of $P$. falciparum and potentially cause a rapid drop in haemoglobin [21]. Previous studies suggested that the severe anaemia during P. malariae infection might be due to prolonged erythrocyte destruction and bone marrow suppression with a

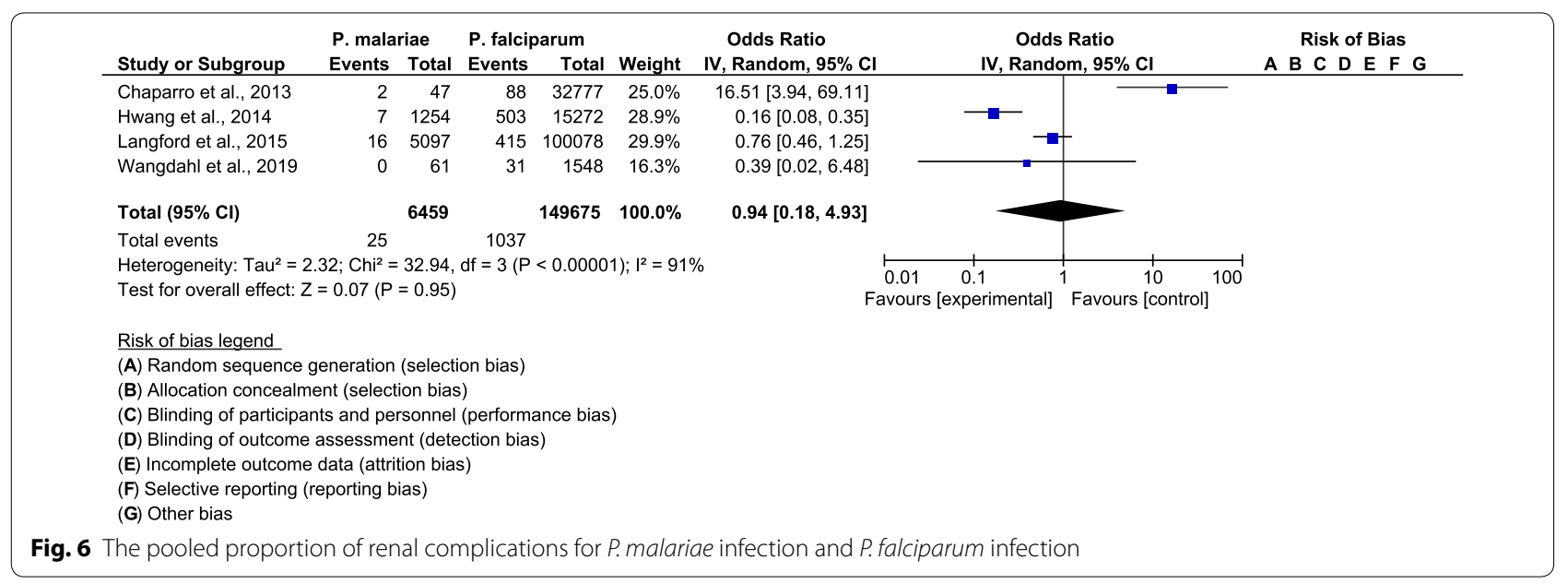


Table 3 Quality of included studies

\begin{tabular}{|c|c|c|c|c|c|c|c|c|c|}
\hline \multirow[t]{2}{*}{ No. } & \multirow[t]{2}{*}{ Reference } & \multicolumn{4}{|l|}{ Selection } & \multirow[t]{2}{*}{ Compatibility } & \multicolumn{3}{|l|}{ Exposure } \\
\hline & & $\begin{array}{l}\text { Is the case } \\
\text { definition } \\
\text { adequate? }\end{array}$ & $\begin{array}{l}\text { Representativeness } \\
\text { of the cases }\end{array}$ & $\begin{array}{l}\text { Selection } \\
\text { of controls }\end{array}$ & $\begin{array}{l}\text { Definition } \\
\text { of controls }\end{array}$ & & $\begin{array}{l}\text { Ascertainment } \\
\text { of exposure }\end{array}$ & $\begin{array}{l}\text { Same method } \\
\text { of ascertainment } \\
\text { for cases } \\
\text { and controls }\end{array}$ & $\begin{array}{l}\text { Non- } \\
\text { response } \\
\text { rate }\end{array}$ \\
\hline 1. & $\begin{array}{l}\text { Bottieau } \\
\text { et al. [26] }\end{array}$ & * & $*$ & * & * & $* *$ & * & * & * \\
\hline 2. & $\begin{array}{l}\text { Chaparro } \\
\text { et al. [23] }\end{array}$ & * & * & * & * & $* *$ & * & * & * \\
\hline 3. & $\begin{array}{l}\text { Douglas } \\
\text { et al.[21] }\end{array}$ & * & & $*$ & * & $* *$ & * & * & * \\
\hline 4. & $\begin{array}{l}\text { Hwang } \\
\text { et al. [24] }\end{array}$ & * & * & * & * & $* *$ & * & * & * \\
\hline 5. & $\begin{array}{l}\text { Langford } \\
\text { et al. [22] }\end{array}$ & * & * & * & * & $* *$ & * & * & * \\
\hline 6. & $\begin{array}{l}\text { Wangdahl } \\
\text { et al. [25] }\end{array}$ & * & * & * & * & $* *$ & * & * & * \\
\hline
\end{tabular}

minimal reduction of erythrocyte lifespan by a low parasitaemia level [21, 22, 34]. It should be noted that most patients with $P$. malariae infection in the included studies were Highland Papuans, who are the ethnic group with the highest risk of severe anaemia caused by nutritional and haematological factors [22]. These factors can potentially contribute to the lower mean haemoglobin level in these patients, as the risk of severe anaemia in $P$. malariae infections was similar to that for $P$. falciparum and $P$. vivax infections after adjusting for ethnicity in the multivariable model [22].

Regarding the age distribution of patients with $P$. malariae infection, the included study by Langford et al., clarified that most patients with $P$. malariae infections were aged more than 15 years, which was older than those with $P$. falciparum, $P$. vivax, and mixed infections, reflecting the low transmission intensity in Indonesia [22]. A low number of patients with $P$. malariae infections were aged less than 5 years (10.9\%), the most vulnerable group affected by malaria [35]. This systematic review and meta-analysis indicated that pulmonary complications and renal impairment were frequently found in patients with $P$. malariae infection. The mechanism of pulmonary complications in patients with severe $P$. malariae infection is unknown. Lung injury in P. malariae malaria might be caused by microvascular sequestration, similar to $P$. falciparum infection, which can increase vascular permeability, resulting in fluid loading and progression to pulmonary oedema [36]. Nevertheless, further study is needed to investigate whether red blood cells parasitized with $P$. malariae cytoadhere to endothelial cells of humans.

Renal impairment and nephrotic syndrome were commonly present in patients with $P$. malariae infection, with a mixed IgM and IgG immune complex located at the renal basement membrane [37]. P. malariae infection has long been recognized as the causative agent of nephrotic syndrome among untreated $P$. malariae infections [29, 38-40]. In addition, albuminuria was commonly seen in patients treated with $P$. malariae for neurosyphilis in the 1930s [41]. Nevertheless, the included study by Langford et al. demonstrated a very low prevalence of nephrotic syndrome $(0.1 \%)$ among 5097 enrolled patients with $P$. malariae infections [22]. Although a lower prevalence of nephrotic syndrome occurred in $P$. malariae infections, the proportion of nephrotic syndrome was higher in P. malariae infection than in infections with the other Plasmodium species [22]. Previous studies demonstrated that $P$. malariae-induced nephrotic syndrome can lead to progressive renal failure, particularly in young adults [42, 43]. P. malariae-induced acute renal failure after treatment with quinine was reported previously. In this case, treatment with intravenous quinine and four rounds of renal dialysis improved the renal function of the patient [12]. An unusual case of transfusion-transmitted $P$. malariae infection in an individual with thalassemia major remained undiagnosed for several months, and the individual eventually developed acute renal failure [15].

Severe malaria caused by $P$. malariae infection is infrequent and is caused by multiple susceptibility genes: 
genes related to inflammation, including tumour necrosis factor (TNF), interleukin-6 (IL-6) and IL-10, macrophage migration inhibitory factor (MIF), angiotensin-converting enzyme (ACE), and catalase; genes for coagulation factors, including plasminogen activator inhibitor (PAI)1; fibrinogen; coagulation factors II, V, VII, and XIII; and genes related to innate immunity, including toll-like receptor (TLR)-2, TLR-4, TLR-5, mannose-binding lectin (MBL), interleukin 1 receptor associated kinase 1 (IRAK1), cluster of differentiation-14 (CD-14), toll interleukin-1 receptor-associated protein (TIRAP), and Nf-kB inhibitor $(\mathrm{I} \kappa \mathrm{B})$ [13]. In addition, a previous study indicated that five important genes, including IRAK-1 rs1059703, CD-14 rs2569190, TNF-beta rs909253, IL-6 rs1800795, and MIF rs755622, were associated with the increased severity of multiple organ dysfunction syndrome in a case of $P$. malariae infection [44].

The present systematic review and meta-analysis had several limitations. First, the number of included studies was limited, which might affect the pooled estimate of severe $P$. vivax malaria prevalence globally. Second, although severe $P$. malariae infection was associated with a high burden of severe anaemia, the quantitative analysis of haemoglobin concentrations in $P$. malariae infection could not be performed, as it was reported quantitatively only in the included study by Douglas et al. [21]. Third, nephrotic syndrome and albuminuria could not be analysed, as only the included study by Langford et al. [22] reported the number of $P$. malariae infections with nephrotic syndrome. Fourth, the age distribution of patients with $P$. malariae infections could not be analysed, as only the included study by Langford et al. reported the age distribution of patients with $P$. malariae infections. Fifth, the parasitaemia level related to severe P. malariae infection could not be analysed, as only the included study by Bottieau et al. [26] reported the parasitaemia level. In view of all results, although the present study reported a low prevalence of severe $P$. malariae infection, those with $P$. malariae infection need to be investigated for anaemia and, if present, treated aggressively to prevent anaemia-related death.

\section{Conclusion}

This systematic review demonstrated the low prevalence and low mortality of severe malaria among patients with P. malariae infection. Severe anaemia, pulmonary complications, and renal impairment were the common complications found in patients with $P$. malariae infection. Despite the low prevalence and mortality of $P$. malariae infection, infected patients need to be investigated for severe anaemia and, if present, treated aggressively to prevent anaemia-related death.

\section{Supplementary information}

Supplementary information accompanies this paper at https://doi. org/10.1186/s12936-020-03344-z.

Additional file 1. Demographic and laboratory data.

Additional file 2. Data for calculate the pooled prevalence estimate of severe P. malariae infection.

Additional file 3. Data for calculate the pooled prevalence estimate of complications for P. malariae malaria.

\section{Abbreviations}

PRISMA: Preferred Reporting Items for Systematic Reviews and Meta-Analyses; $\mathrm{Cl}$ : Confidence interval; OR: Odds ratio; WHO: World Health Organization; RDT: Rapid diagnostic test; PCR: Polymerase chain reaction; NOS: NewcastleOttawa Scale; TNF: Tumour necrosis factor; IL: Interleukin; MIF: Macrophage migration inhibitory factor; ACE: Angiotensin-converting enzyme; PAl: Plasminogen activator inhibitor; TLR: Toll-like receptor; MBL: Mannose-binding lectin; IRAK-1: Interleukin 1 receptor associated kinase 1; CD: Cluster of differentiation; TIRAP: Toll interleukin-1 receptor-associated protein; IKB: Nf-kB inhibitor.

\section{Acknowledgements}

The authors would like to thank all published research that contributed to the data used in this study.

\section{Authors' contributions}

MK, KUK, GDM, and FRM participated in the study design, data analysis, and writing of the paper. All authors read and approved the final paper.

\section{Funding}

This research was partially supported by the new strategic research (P2P) project, Walailak University, Thailand. The funders had a role in the collection, analysis, and interpretation of the data.

\section{Availability of data and materials}

The data sets used during the current study are available in the present manuscript and supplementary files.

\section{Ethics approval and consent to participate}

Not applicable.

\section{Consent for publication}

Not applicable.

\section{Competing Interests}

The authors declare that they have no competing interests.

\section{Author details}

${ }^{1}$ Medical Technology, School of Allied Health Sciences, Walailak University, Tha Sala, Nakhon Si Thammarat, Thailand. ${ }^{2}$ Department of Medical Technology, Far Eastern University, Manila, Philippines.

Received: 30 January 2020 Accepted: 22 July 2020

Published online: 31 July 2020

References

1. WHO. Malaria. Geneva: World Health Organization; 2019. https://www. who.int/news-room/fact-sheets/detail/malaria. Accessed 10 Jan 2020.

2. Kappe SH, Vaughan AM, Boddey JA, Cowman AF. That was then but this is now: malaria research in the time of an eradication agenda. Science. 2010;328:862-6.

3. Trampuz A, Jereb M, Muzlovic I, Prabhu RM. Clinical review: severe malaria. Crit Care. 2003;7:315-23.

4. Kotepui M, Phunphuech B, Phiwklam N, Chupeerach C, Duangmano S. Effect of malarial infection on haematological parameters in population near Thailand-Myanmar border. Malar J. 2014;13:218. 
5. Autino B, Noris A, Russo R, Castelli F. Epidemiology of malaria in endemic areas. Mediterr J Hematol Infect Dis. 2012;4:e2012060.

6. Collins WE, Jeffery GM. Plasmodium malariae: parasite and disease. Clin Microbiol Rev. 2007;20:579-92.

7. Culleton RL, Mita T, Ndounga M, Unger H, Cravo PV, Paganotti GM, et al. Failure to detect Plasmodium vivax in West and Central Africa by PCR species typing. Malar J. 2008;7:174.

8. WHO. Severe falciparum malaria. Trans R Soc Trop Med Hyg 2000;94(Suppl 1):S1-90.

9. WHO. Guidelines for the treatment of malaria. Geneva: World Health Organization; 2015. https://www.who.int/malaria/publications/ atoz/9789241549127/en/. Accessed 12 Jan 2020.

10. Svenson JE, MacLean JD, Gyorkos TW, Keystone J. Imported malaria. Clinical presentation and examination of symptomatic travelers. Arch Intern Med. 1995;155:861-8.

11. Udomsangpetch R, Webster HK, Pattanapanyasat K, Pitchayangkul S, Thaithong S. Cytoadherence characteristics of rosette-forming Plasmodium falciparum. Infect Immun. 1992;60:4483-90.

12. Badiane AS, Diongue K, Diallo S, Ndongo AA, Diedhiou CK, Deme AB, et al. Acute kidney injury associated with Plasmodium malariae infection. Malar J. 2014;13:226

13. Bellanger AP, Bruneel F, Barbot O, Mira JP, Millon L, Houzé $P$, et al. Severe Plasmodium malariae malaria in a patient with multiple susceptibility genes. J Travel Med. 2010;17:201-2.

14. Hedelius R, Fletcher JJ, Glass li WF, Susanti Al, Maguire JD. Nephrotic syndrome and unrecognized Plasmodium malariae infection in a US navy sailor 14 years after departing Nigeria. J Travel Med. 2011;18:288-91.

15. Neri S, Pulvirenti D, Patamia I, Zoccolo A, Castellino P. Acute renal failure in Plasmodium malariae infection. Neth J Med. 2008:66:166-8

16. Tapper ML, Armstrong D. Malaria complicating neoplastic disease. Arch Intern Med. 1976;136:807-10.

17. Rahman W, Chotivanich K, Silamut K, Tanomsing N, Hossain A, Faiz MA, et al. Plasmodium malariae in Bangladesh. Trans R Soc Trop Med Hyg. 2010;104:78-80

18. Moher D, Liberati A, Tetzlaff J, Altman DG, The PRISMA Group. Preferred reporting items for systematic reviews and meta-analyses: the PRISMA statement. PLoS Med. 2009;6:e1000097.

19. Lo CK, Mertz D, Loeb M. Newcastle-Ottawa Scale: comparing reviewers' to authors'assessments. BMC Med Res Methodol. 2014;14:45.

20. Nyaga VN, Arbyn M, Aerts M. Metaprop: a Stata command to perform meta-analysis of binomial data. Arch Public Health. 2014;72:39.

21. Douglas NM, Lampah DA, Kenangalem E, Simpson JA, Poespoprodjo JR, Sugiarto $P$, et al. Major burden of severe anemia from non-falciparum malaria species in southern Papua: a hospital-based surveillance study. PLoS Med. 2013;10:e1001575.

22. Langford S, Douglas NM, Lampah DA, Simpson JA, Kenangalem E, Sugiarto P, et al. Plasmodium malariae infection associated with a high burden of anemia: a hospital-based surveillance study. PLoS Negl Trop Dis. 2015;9:e0004195.

23. Chaparro P, Padilla J, Vallejo AF, Herrera S. Characterization of a malaria outbreak in Colombia in 2010. Malar J. 2013;12:330.

24. Hwang J, Cullen KA, Kachur SP, Arguin PM, Baird JK. Severe morbidity and mortality risk from malaria in the United States, 1985-2011. Open Forum Infect Dis. 2014;1:ofu034.

25. Wangdahl A, Wyss K, Saduddin D, Bottai M, Ydring E, Vikerfors T, et al. Severity of Plasmodium falciparum and non-falciparum malaria in travelers and migrants: a nationwide observational study over 2 decades in Sweden. J Infect Dis. 2019;220:1335-45.

26. Bottieau E, Clerinx J, Van Den Enden E, Van Esbroeck M, Colebunders R, Van Gompel A, et al. Imported non-Plasmodium falciparum malaria: a fiveyear prospective study in a European referral center. Am J Trop Med Hyg. 2006;75:133-8.
27. Cochrane Training. Cochrane handbook for systematic reviews of interventions version 6.0 (updated July 2019); 2019. www.training.cochrane. org/handbook. Accessed 25 Jan 2020.

28. McKenzie FE, Jeffery GM, Collins WE. Plasmodium malariae blood-stage dynamics. J Parasitol. 2001:87:626-37.

29. Maguire JD, Baird JK. The 'non-falciparum' malarias: the roles of epidemiology, parasite biology, clinical syndromes, complications and diagnostic rigour in guiding therapeutic strategies. Ann Trop Med Parasitol. 2010;104:283-301.

30. Karyana M, Burdarm L, Yeung S, Kenangalem E, Wariker N, Maristela R, et al. Malaria morbidity in Papua Indonesia, an area with multidrug resistant Plasmodium vivax and Plasmodium falciparum. Malar J. 2008;7:148.

31. Singh B, Kim Sung L, Matusop A, Radhakrishnan A, Shamsul SS, Cox-Singh $J$, et al. A large focus of naturally acquired Plasmodium knowlesi infections in human beings. Lancet. 2004;363:1017-24.

32. Obare P, Ogutu B, Adams M, Odera JS, Lilley K, Dosoo D, et al. Misclassification of Plasmodium infections by conventional microscopy and the impact of remedial training on the proficiency of laboratory technicians in species identification. Malar J. 2013;12:113.

33. Jongwutiwes S, Putaporntip C, Iwasaki T, Sata T, Kanbara H. Naturally acquired Plasmodium knowlesi malaria in human, Thailand. Emerg Infect Dis. 2004:10:2211-3.

34. McQueen PG. Population dynamics of a pathogen: the conundrum of vivax malaria. Biophys Rev. 2010;2:111-20.

35. WHO. Malaria in children under five. Geneva: World Health Organization; 2018. https://www.who.int/malaria/areas/high_risk_groups/children/en/. Accessed 8 Jan 2020.

36. Charoenpan P, Indraprasit S, Kiatboonsri S, Suvachittanont O, Tanomsup S. Pulmonary edema in severe falciparum malaria. Hemodynamic study and clinicophysiologic correlation. Chest. 1990;97:1190-7.

37. Abdurrahman MBGB, Narayana P, Babaoye FA, Edingeton GM. Immunological aspects of nephrotic syndrome in Northern Nigeria. Arch Dis Child. 1981;56:199-202.

38. Hendrickse RG, Adeniyi A. Quartan malarial nephrotic syndrome in children. Kidney Int. 1979;16:64-74.

39. Gilles HM, Hendrickse RG. Nephrosis in Nigerian children. Role of Plasmodium malariae, and effect of antimalarial treatment. BMJ. 1963;2:27-31.

40. Ehrich JH, Eke FU. Malaria-induced renal damage: facts and myths. Pediatr Nephrol. 2007;22:626-37.

41. Boyd MF. Observations on naturally and artificially induced quartan malaria. Am JTrop Med Hyg. 1940;S1-20:749-97.

42. Hendrickse RG, Adeniyi A, Edington GM, Glasgow EF, White RH, Houba V. Quartan malarial nephrotic syndrome. Collaborative clinicopathological study in Nigerian children. Lancet. 1972;1:1143-9.

43. Eiam-Ong S. Malarial nephropathy. Semin Nephrol. 2003;23:21-33.

44. Descheemaeker PN, Mira JP, Bruneel F, Houze S, Tanguy M, Gangneux $J P$, et al. Near-fatal multiple organ dysfunction syndrome induced by Plasmodium malariae. Emerg Infect Dis. 2009;15:832-4.

\section{Publisher's Note}

Springer Nature remains neutral with regard to jurisdictional claims in published maps and institutional affiliations.

Ready to submit your research? Choose BMC and benefit from:

- fast, convenient online submission

- thorough peer review by experienced researchers in your field

- rapid publication on acceptance

- support for research data, including large and complex data types

- gold Open Access which fosters wider collaboration and increased citations

- maximum visibility for your research: over 100M website views per year

At BMC, research is always in progress.

Learn more biomedcentral.com/submissions 